\title{
DOI: 10.7596/taksad.v6i4.1178
}

Citation: Tscymbalystov, A., Kopytov, A., Saraykina, O., \& Gontarev, S. (2017). Efficiency of Motivation Development Models for Hygienic Skills. Journal of History Culture and Art Research, 6(4), 339-349. doi:http://dx.doi.org/10.7596/taksad.v6i4.1178

\section{Efficiency of Motivation Development Models for Hygienic Skills}

\author{
Alexander V. Tscymbalystov ${ }^{1}$, Alexander A. Kopytov ${ }^{2}$ \\ Olga S. Saraykina ${ }^{3}$, Sergey N. Gontarev ${ }^{4}$
}

\begin{abstract}
The combined influence of a family and a state plays an important role in the development of an individual. This study is aimed at the model effectiveness evaluation concerning the development of oral hygiene skills among children living in families $(n=218)$ and being under the care of a state $(n=229)$. The groups were created among the children who took part in the study: the preschoolers of 5-7 years, schoolchildren of 8-11 years and adolescents of 12-15 years. During the initial examination, the hygienic status of the oral cavity before and after tooth brushing was evaluated. After that, subgroups were formed in each age group according to three models of hygienic skills training: 1) computer presentation lesson; 2) one of the students acted as a demonstrator of the skill; 3) an individual training by a hygienist. During the next 48 hours children did not take hygienic measures. Then the children were invited for a control session to demonstrate the acquired skills of oral care and evaluate the effectiveness of a model developing the skills of individual oral hygiene. During the control examination, the hygienic status was determined before and after the tooth cleaning, which allowed to determine the regimes of hygienic measure performance for children with different social status and the effectiveness of hygiene training models.
\end{abstract}

Keywords: Hygienic skills, Dental status, Training model.

\footnotetext{
${ }^{1}$ Belgorod State University 308015, Russia, Belgorod, Pobedy str., 85.

2 Belgorod State University 308015, Russia, Belgorod, Pobedy str., 85. E-mail: kopitov.aleks@yandex.ru

${ }^{3}$ Belgorod State University 308015, Russia, Belgorod, Pobedy str., 85.

${ }^{4}$ Belgorod State University 308015, Russia, Belgorod, Pobedy str., 85.
} 


\section{Introduction}

Despite the efforts made in the field of practical dentistry, a significant part of the population suffers from oral diseases (World Health Organization, 2003; Moynihan \& Kelly, 2014; Irani et al. 2015). The state policy aimed at the prevention of these diseases includes a number of concepts: accessibility, territoriality, state guarantees, clinical planning, etc. (Soto, 2015). However, the development of oral health skills, carried out at a family and a preclinical level, is one of the most important activities, since the mechanical removal of dental plaque prevents the development of caries and periodontal diseases (Kopytov \& Moscovskaya, 2011; Daurova et al., 2016; Freire, 2013). The habit of brushing your teeth is acquired in childhood and is maintained throughout life. However, as a rule, the tooth brushing in childhood is not very effective, which is explained by the lack of skills and motivation (Zeynalova, 2015). In order to create the proper level of skills and motivation for children, to improve the efficiency of dental cleaning, it is recommended to conduct conversations and demonstrations at a dental reception, and intra-family communication is also important (Nekhoroshev et al., 2010). However, in the era of social instability, the number of children whose dominance of socialization is the absence of a home and the formation of depressive symptoms associated with a lack of a family increases (Istratova \& Vapelnik, 2014). From this point of view, the peculiarities of hygienic skills assimilation by the children who lost family care is of particular importance (Wagstaff et al., 1991; Cheng, 2008). In our opinion, the studies on the distinctive features of hygienic skills development among children growing outside the family atmosphere can provide the analytical material for the development of strategies strengthening dental health that are most appropriate for this population group.

The purpose of the study is to evaluate the relationship between the social status of a child, and the effectiveness of models to form the motivation for individual hygiene procedure performance.

\section{Materials and methods}

446 children participated in the study. 218 children living in complete families were placed in FF (Full Families) group. This group included 72 preschoolers at the age of 5-7 years, 72 junior schoolchildren at the age of 8-11 years and 74 teenagers at the age of 12-15 years. Group G (Goverment) was made up of 229 children under the care of the state. Of these, 74 were preschool children at the age of 5-7 years. Younger schoolchildren at the age of 8-11 and adolescents at the age of 12-15 made 73 and 82 respectively. Children were divided into subgroups, depending on the model of hygiene skill training. In the subgroups Computer Presentation (CP), the motivation for oral hygiene performance was formed using computer presentations. In the subgroups of Children Demonstration (CD), children participated in the 
study and acted as demonstrators. In the Individual Training (IT) subgroups each child was given an individual training by a hygienist. The distribution of children by subgroups is shown in tables $1,2$.

Table 1. Distribution of children living in complete families by subgroups $(\mathrm{n}=218)$

\begin{tabular}{|c|c|c|c|c|c|c|c|c|c|}
\hline Age & \multicolumn{3}{|c|}{$\begin{array}{l}\text { Preschoolers at the age } \\
\text { of } \\
\text { 5-7years }(n=72)\end{array}$} & \multicolumn{3}{|c|}{$\begin{array}{l}\text { Minor schoolchildren at } \\
\text { the age of } \\
\text { 8-11years }(n=72)\end{array}$} & \multicolumn{3}{|c|}{$\begin{array}{l}\text { Teenagers at the age of } \\
12-15 \text { years }(n=74)\end{array}$} \\
\hline $\begin{array}{c}\text { Training } \\
\text { model }\end{array}$ & $\begin{array}{c}\text { FFCP } \\
*\end{array}$ & $\begin{array}{c}\text { FFCD } \\
* *\end{array}$ & $\begin{array}{r}\text { FFIT } \\
* * *\end{array}$ & $\begin{array}{c}\text { FFCP } \\
*\end{array}$ & $\begin{array}{c}\text { FFCD } \\
* *\end{array}$ & $\begin{array}{l}\text { FFIT } \\
* * *\end{array}$ & $\begin{array}{c}\text { FFCP } \\
*\end{array}$ & $\begin{array}{c}\text { FFCD } \\
* *\end{array}$ & $\begin{array}{r}\text { FFIT } \\
* * *\end{array}$ \\
\hline $\begin{array}{c}\text { Number of } \\
\text { children }\end{array}$ & 22 & 25 & 25 & 24 & 26 & 22 & 23 & 25 & 26 \\
\hline
\end{tabular}

* Children living in complete families and gaining hygienic skills, using computer presentations

** Children living in complete families gaining hygienic skills by showing them to each other *** Children living in complete families and gaining hygienic skills through an individual training by a hygienist

Table 2. Distribution of children under state care by subgroups $(\mathrm{n}=229)$

\begin{tabular}{|c|c|c|c|c|c|c|c|c|c|}
\hline Age & \multicolumn{3}{|c|}{$\begin{array}{l}\text { Preschoolers at the age } \\
\text { of } \\
\text { 5-7years }(n=74)\end{array}$} & \multicolumn{3}{|c|}{$\begin{array}{l}\text { Minor schoolchildren at } \\
\text { the age of } \\
\text { 8-11years }(n=73)\end{array}$} & \multicolumn{3}{|c|}{$\begin{array}{l}\text { Teenagers at the age of } \\
12-15 \text { years }(n=82)\end{array}$} \\
\hline $\begin{array}{c}\text { Training } \\
\text { model }\end{array}$ & $\begin{array}{c}\text { GCP } \\
*\end{array}$ & $\begin{array}{c}\text { GCD } \\
* *\end{array}$ & $\begin{array}{l}\text { GIT } \\
* * *\end{array}$ & $\begin{array}{c}\text { GCP } \\
*\end{array}$ & $\begin{array}{c}\text { GCD } \\
* *\end{array}$ & $\begin{array}{l}\text { GIT } \\
* * *\end{array}$ & $\begin{array}{c}\text { GCP } \\
*\end{array}$ & $\begin{array}{c}\text { GCD } \\
* *\end{array}$ & $\begin{array}{l}\text { GIT } \\
* * *\end{array}$ \\
\hline $\begin{array}{c}\text { Number of } \\
\text { children }\end{array}$ & 27 & 24 & 23 & 24 & 26 & 23 & 29 & 23 & 30 \\
\hline
\end{tabular}

* Children under a state care, who acquire hygiene skills, using computer presentations

** Children under a state care, who acquire hygienic skills, demonstrating them to each other 
*** Children under a state care, who acquire hygiene skills through an individual training by a hygiene expert

During an initial visit, the hygienic status of the child oral cavity was evaluated, by applying six lower incisors of iodine-iodide-potassium solution to the labial surface, followed by the assessment of the staining area. In the absence of incisors, the solution covered the lower canines on the corresponding side. In order to perform the statistical evaluation, the following criteria were adopted: 0 points in the absence of staining, 1 point for weak staining (and less than $1 / 4$ of a crown area) and 2 points for other colorimetric changes. After that, in accordance with the previously formed skills, the children brushed their teeth and evaluated the effectiveness of their hygienic skills. During the next stage, after a training session, in accordance with the models of hygienic skill acquisition: using computer presentations CP, demonstrating the skills to each other $\mathrm{CD}$, through an individual training by a hygienist IT, the children under the guidance of a hygienist removed dental plaque by soft toothbrushes of S category (soft) using the toothpaste "Zhemchug". Then the children were given the following task: not to brush their teeth within 48 hours. Then the children were invited to a control visit. The evaluation of hygienic status by the control method was carried out before and after tooth brushing. Comparing the data obtained before tooth brushing during the primary and control visit, they made conclusions about the dental cleaning regimens. Based on the obtained data after tooth brushing, we made the conclusion about the effectiveness of the model forming the skills of individual oral hygiene.

\section{Study Results}

During the primary visit they revealed that in the group of preschoolers (5-7 years) living in full families the hygiene index corresponded to $1.37 \pm 0.33$. Among younger schoolchildren at the age of 8-11 years, the index of oral hygiene was slightly lower than among the children at the age of 5-7 years and was $1.33 \pm 0.37$. Adolescents (12-15 years old) showed the best hygienic status of the oral cavity, their hygiene index was $1.16 \pm 0.4$. After tooth cleaning, the hygiene index decreased in all groups. Preschool children had the decrease down to $1.11 \pm$ 0.29 , which was $19 \%$ of the initial data. Among younger schoolchildren, the hygiene index was $1.04 \pm 0.23$, and among adolescents - $0.88 \pm 0.19$, which made $21.8 \%$ and $24.1 \%$, respectively (Table 3). 
Table 3. The values of hygiene index before and after tooth brushing during an initial visit

\begin{tabular}{|c|c|c|c|c|c|c|}
\hline & \multicolumn{3}{|c|}{ Children living in full families } & \multicolumn{3}{c|}{ Children under a state care } \\
\hline Age & $5-7$ years & $8-11$ years & $12-15$ years & $5-7$ years & $8-11$ years & $12-15$ years \\
\hline $\begin{array}{c}\text { Before } \\
\text { brushing }\end{array}$ & $1.37 \pm 0.33$. & $1.33 \pm 0,37$ & $1.16 \pm 0,4$ & $1.54 \pm 0,29$ & $1.43 \pm 0.41$ & $1.38 \pm 0,33$. \\
\hline $\begin{array}{c}\text { After } \\
\text { brushing }\end{array}$ & $1.11 \pm 0.29^{*}$ & $1.04 \pm 0,23^{*}$ & $0.88 \pm 0,19^{*}$ & $1.3 \pm 0,31^{*}$ & $1.14 \pm 0.27^{*}$ & $1.17 \pm 0,21^{*}$ \\
\hline $\begin{array}{c}\text { Reduction } \\
\%\end{array}$ & 19.0 & 21.8 & 24.1 & 15.6 & 20.3 & 15.2 \\
\hline
\end{tabular}

* The differences in hygiene status are reliable at $\mathrm{p} \leq 0.05$

During a primary visit the preschoolers of 5-7 years old under the care of the state had the worst hygienic condition of the oral cavity. In this subgroup, the hygiene index was determined within $1.54 \pm 0.29$. The junior schoolchildren (8-11 years) had the hygiene index of $1.43 \pm 0.41$, adolescents (12-15 years) $-1.38 \pm 0.33$. The conduct of hygienic measures led to a soft plaque volume decrease, preschoolers had the hygiene index within $1.3 \pm 0.31$, the decrease made 15.6\%. Younger schoolchildren had the reduction of hygienic index by $20.3 \%$, down to $1.14 \pm 0.27$, adolescents had the reduction by $15.2 \%$, down to $1.17 \pm 0.21$ (Table 3 ). Having received the initial data on the skills of individual oral hygiene conduct with children, divided into subgroups, they conducted a training session in accordance with the models of hygienic skill acquisition: using computer presentations (CP), demonstrating skills to each other (CD), and through an individual training by a hygienist (IT). At the end of the lesson, the children were given a task not to brush their teeth for 48 hours, and then had to make a control visit.

Evaluation of dental cleaning regimens: After 48 hours, after the training session, the assessment of the amount of soft plaque was made during the control visit. The pre-school children living in complete families, had the hygiene index within $1.36 \pm 0.47$, the hygiene index of younger schoolchildren made $1.31 \pm 0.52$. As compared with the data received during a primary visit, the index fell by $0.7 \%$ and $1.5 \%$, respectively. In the group of 
adolescents, the hygiene index increased by $6.9 \%$ and reached $1.24 \pm 0.4$. The ratio of the hygiene index values during a primary and a control visit is shown in Table 4.

Table 4. Comparative evaluation of hygiene index before tooth cleaning, during primary and secondary visit

\begin{tabular}{|c|c|c|c|c|c|c|}
\hline & \multicolumn{3}{|c|}{ Children living in full families } & \multicolumn{3}{c|}{ Children under a state care } \\
\hline Age & $5-7$ years & $8-11$ years & $12-15$ years & $5-7$ years & $8-11$ years & 12 -15 years \\
\hline $\begin{array}{c}\text { Primary } \\
\text { visit before } \\
\text { brushing }\end{array}$ & $1.37 \pm 0.33$. & $1.33 \pm 0,37$ & $1.16 \pm 0,4$ & $1.54 \pm 0,29$ & $1.43 \pm 0,41$ & $1.38 \pm 0.33$. \\
\hline $\begin{array}{c}\text { Secondary } \\
\text { visit } \\
\text { before } \\
\text { brushing }\end{array}$ & $1.36 \pm 0.47$ & $1.31 \pm 0,52$ & $1.24 \pm 0,4$ & $1.44 \pm 0,62$ & $1.39 \pm 0,68$ & $1.51 \pm 0.29$ \\
\hline $\begin{array}{c}\text { Dynamics } \\
\%\end{array}$ & $\downarrow 0.7$ & $\downarrow 1.5$ & $\uparrow 6.9^{*}$ & $\downarrow 6.5^{*}$ & $\downarrow 2.8$ & $\uparrow 9.4^{*}$ \\
\hline
\end{tabular}

* Hygiene index dynamics is reliable at $\mathrm{p} \leq 0.05$

During the control visit the preschool children under the care of a state had the hygiene index reduction by $6.5 \%$, down to $1.44 \pm 0.62$. In the group of junior schoolchildren, a slight index decrease was found, down to $1.39 \pm 0.68$, which made $2.8 \%$. Among adolescents, the hygiene index increased by $9.4 \%$, reaching the value of $1.51 \pm 0.29$. The ratio of the hygiene index values during a primary and a control visit is shown in Table 4.

The evaluation of the model effectiveness teaching the hygienic skills of oral care among various groups of children: At the next stage, the children brushed their teeth, in accordance with the newly acquired skills, the hygiene index was determined again at the end of the procedure. In order to calculate the effectiveness of hygienic skill acquisition models using computer presentations $\mathrm{CP}$, demonstrating skills to each other $\mathrm{CD}$, through individual training by a hygienist IT, they took the values of the hygienic index obtained during the primary visit after hygiene procedures as $100 \%$. 
Among the children living in complete families and of all age categories, united in the subgroups of hygienic skills acquisition by the means of computer presentations (CP) the hygiene index underwent an insignificant decrease by $2.3 \%-4.8 \%$ as compared with the value received during a primary visit. In the subgroups of children living in complete families, trained in hygiene by demonstrating the skills to each other (CD) the hygiene index among preschoolers dropped by $9.0 \%$, among minor schoolchildren and adolescents by $13.2 \%$ and 25.9\%, respectively. In the subgroups of children living in complete families and acquiring dental cleaning skills through individual training by a hygienist (IT) the hygienic index has decreased by $18.1 \%$ among preschool children, by 33.6\% among minor schoolchildren, and by $46.5 \%$ among adolescents. The decrease in hygiene index values, depending on the model of hygienic skills training, is presented in Table 5.

Table 5. The dynamics of the hygiene index among the children living in complete families, calculated by the comparison of its values after tooth brushing before and after a training session in accordance with the models CP, CD, IT

\begin{tabular}{|c|c|c|c|c|c|c|c|c|c|}
\hline Age group & \multicolumn{3}{|c|}{$\begin{array}{l}\text { Preschoolers } \\
\text { 5-7 years }\end{array}$} & \multicolumn{3}{|c|}{$\begin{array}{c}\text { Minor schoolchildren } \\
\text { 8-11years }\end{array}$} & \multicolumn{3}{|c|}{$\begin{array}{l}\text { Adolescents } \\
12-15 \text { years }\end{array}$} \\
\hline $\begin{array}{l}\text { The values of the } \\
\text { hygiene index after }\end{array}$ & \multicolumn{3}{|c|}{$1,11 \pm 0,29$} & \multicolumn{3}{|c|}{$1,04 \pm 0,23$} & \multicolumn{3}{|c|}{$0,88 \pm 0,19$} \\
\hline Training model & $\begin{array}{c}\text { FFCP } \\
*\end{array}$ & $\begin{array}{c}\text { FFCD } \\
* *\end{array}$ & $\begin{array}{l}\text { FFIT } \\
* * *\end{array}$ & $\begin{array}{c}\text { FFCP } \\
*\end{array}$ & $\begin{array}{c}\text { FFCD } \\
* *\end{array}$ & $\begin{array}{l}\text { FFIT } \\
* * *\end{array}$ & $\begin{array}{c}\text { FFCP } \\
*\end{array}$ & $\begin{array}{c}\text { FFCD } \\
* *\end{array}$ & $\begin{array}{l}\text { FFIT } \\
* * *\end{array}$ \\
\hline $\begin{array}{c}\text { The values of the } \\
\text { hygiene index after } \\
\text { tooth brushing during } \\
\text { a secondary visit }\end{array}$ & $\begin{array}{c}1.08 \pm \\
0.19\end{array}$ & $\begin{array}{c}1.03 \pm \\
0.16\end{array}$ & $\begin{array}{c}0.92 \pm \\
0.19\end{array}$ & $\begin{array}{c}0.99 \pm \\
0.16\end{array}$ & $\begin{array}{c}0.91 \pm \\
0.14\end{array}$ & $\begin{array}{c}0.69 \pm \\
0.12\end{array}$ & $\begin{array}{c}0.85 \pm \\
0.13\end{array}$ & $\begin{array}{c}0.64 \pm \\
0.09\end{array}$ & $\begin{array}{c}0.47 \pm \\
0.09\end{array}$ \\
\hline $\begin{array}{l}* * * * \text { The revealed } \\
\text { efficiency of the } \\
\text { training model\% }\end{array}$ & 4.6 & 9.0 & 18.1 & 4.8 & 13.2 & 33.6 & 2.3 & 25.9 & 46.5 \\
\hline
\end{tabular}

* Children living in complete families and gaining hygienic skills by the use of computer presentations 
** Children living in complete families and gaining hygienic skills by showing them to each other

*** Children living in complete families and gaining hygienic skills through an individual training by a hygienist

**** Decrease is reliable at $\mathrm{p} \leq 0.05$.

The children under the care of the state, combined in subgroups of hygienic skill acquisition through computer presentations (CP) had a reduced hygiene index: by 5.3\% for preschool children, by $6.1 \%$ for younger schoolchildren, by $10.2 \%$ for adolescents. The subgroups where the children studying hygiene showed the skills to each other had a more pronounced index decrease: preschool children had the reduction by $10.7 \%$, minor schoolchildren $-17.5 \%$ and adolescents - 29.9\%. The maximum decrease of hygiene index is observed in the subgroups of those acquiring dental cleaning skills through individual training by a hygienist (IT). Preschool children had the index reduction by $25.3 \%$, minor schoolchildren by $37.7 \%$ and adolescents by $54.7 \%$. The decrease of hygiene index values, depending on the model of hygienic skills training, is presented in Table 6.

Table 6. Hygiene index dynamics among the children under state care to compare its values after tooth brushing, before and after the training session in accordance with the models CP, CD, IT

\begin{tabular}{|c|c|c|c|c|c|c|c|c|c|}
\hline Age group & \multicolumn{3}{|c|}{$\begin{array}{l}\text { Preschoolers } \\
\text { 5-7 years }\end{array}$} & \multicolumn{3}{|c|}{$\begin{array}{c}\text { Minor schoolchildren } \\
\text { 8-11years }\end{array}$} & \multicolumn{3}{|c|}{$\begin{array}{l}\text { Adolescents } \\
12-15 \text { years }\end{array}$} \\
\hline $\begin{array}{l}\text { The values of the } \\
\text { hygiene index after } \\
\text { tooth brushing teeth }\end{array}$ & \multicolumn{3}{|c|}{$1.3 \pm 0.31^{*}$} & \multicolumn{3}{|c|}{$1.14 \pm 0.27^{*}$} & \multicolumn{3}{|c|}{$1.17 \pm 0.21^{*}$} \\
\hline Training model & $\begin{array}{c}\text { GCP } \\
*\end{array}$ & $\begin{array}{l}\text { GCD } \\
* *\end{array}$ & $\begin{array}{l}\text { GIT } \\
* * *\end{array}$ & $\begin{array}{c}\text { GCP } \\
*\end{array}$ & $\begin{array}{l}\text { GCD } \\
* *\end{array}$ & $\begin{array}{l}\text { GIT } \\
* * *\end{array}$ & $\begin{array}{c}\text { GCP } \\
*\end{array}$ & $\begin{array}{l}\text { GCD } \\
* *\end{array}$ & $\begin{array}{l}\text { GIT } \\
* * *\end{array}$ \\
\hline $\begin{array}{l}\text { The values of the } \\
\text { hygiene index after } \\
\text { tooth brushing teeth } \\
\text { during the secondary } \\
\text { visit }\end{array}$ & $\begin{array}{l}1.23 \pm \\
0.18\end{array}$ & $\begin{array}{l}1.16 \pm \\
0.12\end{array}$ & $\begin{array}{l}0.97 \pm \\
0.09\end{array}$ & $\begin{array}{l}1.07 \pm \\
0.12\end{array}$ & $\begin{array}{l}0.94 \pm \\
0.11\end{array}$ & $\begin{array}{c}0.71 \pm \\
0.09\end{array}$ & $\begin{array}{r}1.05 \pm \\
0.13\end{array}$ & $\begin{array}{l}0.82 \pm \\
0.09\end{array}$ & $\begin{array}{r}0.53 \pm \\
0.08\end{array}$ \\
\hline $\begin{array}{c}* * * * \text { The revealed } \\
\text { efficiency of training } \\
\text { model\% }\end{array}$ & 5.3 & 10.7 & 25.3 & 6.1 & 17.5 & 37.7 & 10.2 & 29.9 & 54.7 \\
\hline
\end{tabular}


* The children under a state care, who acquire hygienic skills, using computer presentations ** The children under a state care, who acquire hygienic skills demonstrating them to each other

*** The children under a state care, who acquire hygienic skills through individual training by a hygienist

$* * * *$ The index reduction is reliable at $\mathrm{p} \leq 0.05$.

\section{Discussion}

Comparing the data obtained before tooth brushing during the primary and control visit, they concluded about the dental cleaning regimens. If a child does not clean his teeth within 48 hours, two options are possible. 1 . If a child has the habit to brush his teeth twice a day, then three cleanings are missed by him. 2. If there is a habit to brush your teeth once a day, then one cleaning is missed. Since preschool children under a state care have the hygiene index reduction by $6.5 \%$ after a 48 -hour absence of hygienic measures, it can be assumed that there is a norm to clean teeth 1 time in 2-3 days or less in this social group of children. Since the preschoolers and junior schoolchildren living in complete families, as well as the younger schoolchildren under the care of a state have almost unchanged hygienic index, it must be assumed that this category of children cleans teeth 1 time in two days. The increase of the hygienic index among adolescents after a 48-hour absence of hygiene procedures by $6.5 \%$ $9.4 \%$, gives the right to assert that the habit of brushing teeth 1-2 times a day has developed in this age group.

Assessing the hygienic status of children who participated in the study, it should be noted that all relevant age groups of the children living in complete families had the hygienic status of the oral cavity better than the hygienic status of children under a state care. At the same time, regardless of the model of used to teach oral hygiene skills among the children under a state care, the dynamics of the hygiene index decline was more pronounced than among the children living in complete families. In our opinion, this phenomenon is explained by the fact that children staying in the information and communication space of a state institution initiate a more intensive or a longer discussion of the proposed models (hygienic skills) by themselves. Interfamily communication between parents, concerned with social problems and with somatically healthy children, affects, as a rule, to a lesser extent the activities carried out with children in medical and preventive institutions.

The implementation of the model based on computer presentations within the groups of children living in complete families led to the hygiene index reduction by $2.3 \%-4.8 \%$, which leads to the conclusion that children did not perceive there lesson as a significant measure which influences their health. The groups of children under a state care, had computer 
presentations which led to hygiene index reduction by $5.3 \%-10.2 \%$. An average dynamics of hygiene index among children after computer presentations, allows to recommend this training model as an auxiliary one, when you teach the hygienic skills of oral care.

The application of the model teaching the hygienic skills of oral care, where the children participating in the study were demonstrators, did not imply a playful form of training. This is conditioned by the fact that it is practically impossible for a learner to reflect arbitrarily within the model combining the game and medical component. Thus, not only play activity suffers, but also the learning process itself. The model where children acted as demonstrators appeared to be relevant because it was implied that educational children would be more effective in hygienic skills demonstration at the usual informational and communicative level, which was not revealed in the study. The dynamics of the hygienic index reduction caused by the use of this model was within $9.0 \%-29.9 \%$.

The model of oral care habit development in the process of individual training by a hygienist demonstrated the greatest effectiveness. The decrease of the hygiene index after its implementation is diagnosed within $18.1 \%$ - 54.7\%. The high dynamics of reduction is conditioned by the ability of an expert to correct incorrect actions of students in a timely manner during the learning process. The greatest part of time was spent on it.

In summary, the urgency of dentistry tasks is determined by their social importance, the need to preserve and promote health, the least protected strata of population, including the children who lost their families and are under a state care. In order to prevent major dental diseases, this category of population has to plan the possibility of individual sessions with children by dental hygienists. Other models of dental skill teaching may be used only as auxiliary ones.

\section{References}

Cheng, N. F.; Han, P. Z. \& Gansky, S. A. (2008). Methods and software for estimating health disparities: the case of children's oral health. American Journal of Epidemiology, 168(8), 906914. DOI:10.1093/aje/kwn207.

Daurova, F. Yu.; Makeeva, M. K.; Kodzaeva, Z. S.; Taraki, F. \& Tomaeva, D. I. (2016). Hygiene level increase among adult patients through hygienic briefing. International Scientific and Research Journal, 5(47), 141-145.

Freire, M. C. M.; Reis, S. C. G. B.; Figueiredo, N.; Peres, K. G.; Moreira, R. S. \& Antunes, J. L. F. (2013). Determinantes individuais e contextuais da carie em crianças brasileiras de 12 anos em 2010. Rev Saude Publica, 3(47), 40-49. 
Irani, F. C.; Wassall, R. R. \& Preshaw, P. M. (2015). Impact of periodontal status on oral health-related quality of life in patients with and without type 2 diabetes. Journal of Dentistry, 43(5), 506-511.

Istratova, O. N. \& Vapelnik, L. A. (2014). The features of personal helplessness manifestation among social adolescent orphans. Actual problems of the humanities and natural sciences, 9, 372-377.

Kopytov, A. A. \& Moscovskaya, N. B. (2011). The impact of fast food products on the biocenosis of the dentogingival pocket, damaged by periodontal therapy. Scientific bulletins of the Belgorod State University. Series: Medicine. Pharmacy, 10(14), 231-235.

Moynihan, P. J. \& Kelly, S. (2014). Effect on caries of restricting sugars intake: systematic review to inform WHO guidelines. J. Dent Res., 93(1), 8-18. DOI: $10.1177 / 0022034513508954$.

Nekhoroshev, A. S.; Danilova, N. B. \& Morozova, E. I. (2010). Methodological aspects of training program use in oral hygiene by practicing dentists. Preventive and clinical medicine, 2(35), 48-51.

Soto, R. G. C. (2015). Influence of scheduling in clinical dental care on indicators of oral health. Rev. Gaúch. Odontol., 3(63), 283-290.

Wagstaff, A.; Paci P. \& Van Doorslaer, E. (1991). On the measurement of inequalities in health. Social Science \& Medicine, 33(5), 545-557. DOI: 10.1016/0277-9536(91)90212-U.

World Health Organization (2003). The World Oral Health Report 2003: continuous improvement of oral health in the 21st century: the approach of the WHO Global Oral Health Programme. Geneva: World Health Organization.

Zeynalova, G. K.; Alieva, R. K. \& Garaev, Z. I. (2015). Organization of health education for the prevention of major dental diseases among primary school children in Azerbaijan. Medicus, 4(4), 99-101. 